\title{
Fuzzy Logic - Based Approach for Adaptive Hysteresis Band and Dc Voltage Control in Shunt Active Filter
}

\author{
P. Rathika and Dr. D. Devaraj
}

\begin{abstract}
Active filters are widely employed in distribution system to reduce the harmonics. In this paper, a fuzzy logiccontrolled shunt active power filter capable of reducing the total harmonic distortion is developed. The instantaneous $\mathbf{p - q}$ theory is used for calculating the compensating current. Fuzzy-adaptive hysteresis band technique is adopted for the current control to derive the switching signals for the voltage source inverter. The fuzzy-adaptive hysteresis band current controller changes the hysteresis bandwidth according to the supply voltage and the slope of the reference compensator current wave. A fuzzy logic-based controller is developed to control the voltage of the DC capacitor. Simulation results obtained are presented and compared with the conventional controller. Simulation results show the effectiveness of the proposed technique for harmonic reduction.
\end{abstract}

Index Terms - Active power filter (APF), harmonics, hysteresis band, fuzzy logic control

\section{INTRODUCTION}

Harmonic distortion is one of the main power quality disturbances frequently encountered by the utilities. The harmonic disturbances in the power supply are caused by the non-linear characteristics of the loads. The presence of harmonics leads to transformer heating, electromagnetic interference and solid state device malfunction. Hence, it is necessary to reduce the dominant harmonics below $5 \%$ as specified in IEEE 519-1992 harmonic standard [1].

Conventionally, passive L-C filters [2- 4] were used to eliminate line harmonics. However, the passive filters have the demerits of fixed compensation, bulkiness and occurrence of resonance with other elements. The recent advances in power semiconductor devices have resulted in the development of Active Power Filters (APF) for harmonic suppression. Various topologies of active filters have been proposed for harmonic mitigation. The shunt APF based on Voltage Source Inverter (VSI) structure is an attractive solution to harmonic current problems. The shunt active filter is a pulse width modulated (PWM) voltage source inverter (VSI) that is connected in parallel with the load. It has the capability to inject harmonic current into the $\mathrm{AC}$ system with the same amplitude but opposite phase than

Manuscript received July 21, 2009.

P.Rathika, Lecturer, Dr.Sivanthi Aditanar College of Engineering, Tiruchendur, Tamilnadu 628215, India (Phone: 09344296887; e-mail: rathikasakthikumar@yahoo.co.in).

Dr.D.Devaraj, Professor and Head, Electrical and Electronics Engineering Department, Arulmigu Kalasalingam College of Engineering, Krishnankoil, Tamilnadu, India(e-mail: deva230@yahoo.com) that of the load $[1,2]$.

The principal components of the APF are the VSI, a DC energy storage device that in this case is capacitor, a coupling transformer and the associated control circuits. The performance of an active filter depends mainly on the technique used to compute the reference current and the control method used to inject the desired compensation current into the line.

There are two major approaches that have emerged for the harmonic detection [2], namely, time domain and the frequency domain methods. The frequency domain methods include, Discrete Fourier Transform (DFT), Fast Fourier Transform (FFT), and Recursive Discrete Fourier Transform (RDFT) based methods. The frequency domain methods require large memory, computation power and the results provided during the transient condition may be imprecise [4]. On the other hand, the time domain methods require less calculations and are widely followed for computing the reference current. The two mostly used time domain methods are synchronous reference (d-q-0) theory and instantaneous real-reactive power (p-q) theory. Instantaneous $\mathrm{p}-\mathrm{q}$ theory is followed in this work.

There are several current control strategies proposed in the literature [4-8], namely, PI control, Average Current Mode Control (ACMC), Sliding Mode Control (SMC) and hysteresis control. Among the various current control techniques, hysteresis control is the most popular one for active power filter applications. Hysteresis current control [9] is a method of controlling a voltage source inverter so that the output current is generated which follows a reference current waveform. The current control with a fixed hysteresis band has the disadvantage that the switching frequency varies within a band because peak - to peak current ripple is required to be controlled at all points of the fundamental frequency wave. Kale et al [10] have proposed an adaptive band controller for APF. The adaptive hysteresis band controller changes the hysteresis bandwidth as a function of reference compensator current variation to optimize switching frequency and THD of supply current. This paper proposes a fuzzy-adaptive hysteresis band control, where the hysteresis bandwidth can be easily calculated with the help of a fuzzy logic controller (FLC).

Another important task in the active filter design is the maintenance of constant DC voltage across the capacitor connected to the inverter. This is necessary because there is energy loss due to conduction and switching power losses associated with the diodes and IGBTs of the inverter in APF, which tend to reduce the value of voltage across the DC capacitor. Generally, PI controller [8] is used to control the DC bus voltage. The PI controller based approach requires 
precise linear mathematical model which is difficult to obtain. Also, it fails to perform satisfactorily under parameter variations, non-linearity, and load disturbances [12]. This paper proposes a fuzzy logic controller for D.C voltage control.

Computer simulations are carried out on a sample power system to demonstrate the effectiveness of the proposed approach in suppressing the harmonics.

\section{Control Strategy For Shunt Active Filter}

The performance of the active filter mainly depends on the methodology adopted to generate the reference current and the control strategy adopted to generate the gate pulses.

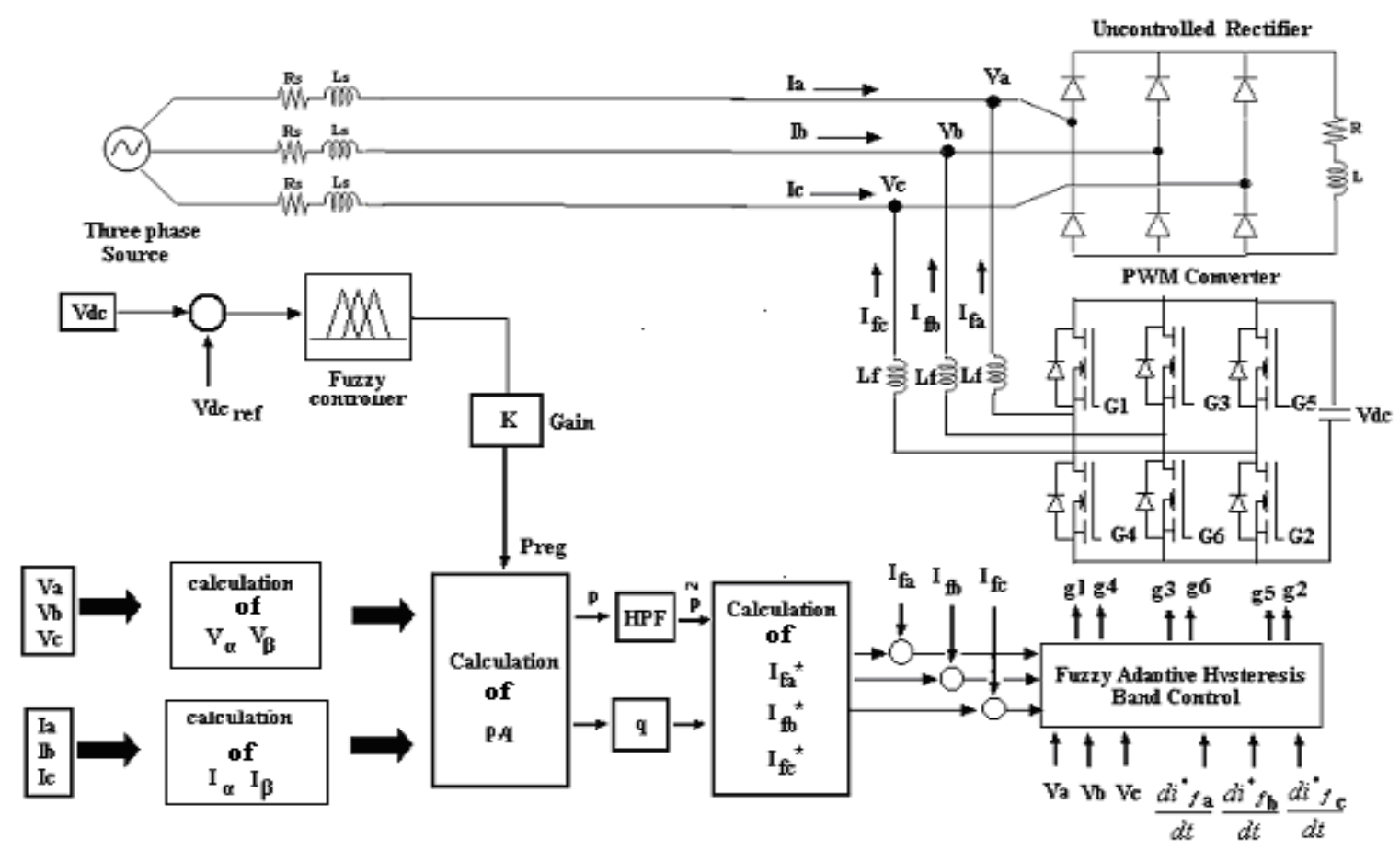

Fig.1. Active Power Filter with the proposed control technique

The block diagram representation of the proposed control strategy for the shunt active filter is shown in Fig.1. The control strategy is implemented in three stages. In the first stage, the essential voltage and current signals are measured to gather accurate system information. In the second stage, compensating currents are derived based on instantaneous $\mathrm{p}-\mathrm{q}$ theory. In the third stage, the gating signals for the solid-state devices are generated using hysteresis-based current control method. The instantaneous p-q theory [8] is based on " $\alpha-\beta$ " transformation of voltage and current signals to derive compensating signals. The instantaneous active and reactive power can be computed in terms of transformed voltage and current signals. From instantaneous active and reactive powers, harmonic active and reactive powers are extracted using low-pass and high-pass filters. From harmonic active and reactive powers, using reverse " $\alpha-\beta$ " transformation, compensating commands in terms of currents are derived. The detail of $\mathrm{p}$-q theory is given in Appendix A.

Hysteresis current controller derives the switching signals of the inverter power switches in a manner that reduces the current error. The switches are controlled asynchronously to ramp the current through the inductor up and down so that it follows the reference. The current ramping up and down between two limits is illustrated in Fig.2. When the current through the inductor exceeds the upper hysteresis limit a negative voltage is applied by the inverter to the inductor. This causes the current in the inductor to decrease. Once the current reaches the lower hysteresis limit a positive voltage is applied by the inverter to the inductor and this causes the current to increase and the cycle repeats.

The current controllers of the three phases are designed to operate independently. Each current controller determines the switching signals to the inverter. The switching logic for phase $\mathrm{A}$ is formulated as below:

If $i f a<\left(i^{*} f a-\mathrm{HB}\right)$ upper switch (G1) is OFF and lower switch (G4) is ON

If $i_{f a}<\left(i_{f a}^{*}+\mathrm{HB}\right)$ upper switch (G1) is $\mathrm{ON}$ and lower switch (G4) is OFF

In the same fashion, the switching of phase $\mathrm{B}$ and $\mathrm{C}$ devices are derived.

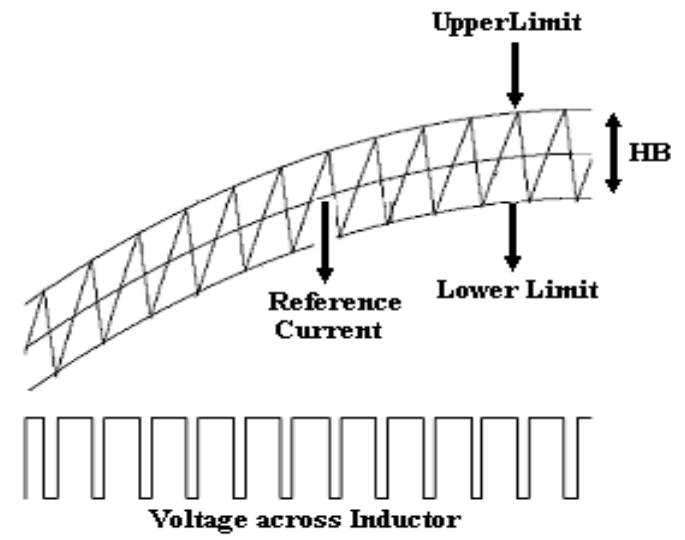


Fig.2. Hysteresis Current Control Operation Waveform

This method has the drawbacks of variable switching frequency, heavy interference between the phases in case of three phase active filter with isolated neutral and irregularity of the modulation pulse position [10]. These drawbacks provide high current ripples, acoustic noise and difficulty in designing input filter. To overcome these undesirable drawbacks, this paper presents a adaptive hysteresis band control in which the band width can be determined by the fuzzy logic controller. The adaptive hysteresis band (HB) can be modulated at different points of the fundamental frequency of the cycle to control the PWM switching pattern of the inverter. The implementation of this method is discussed in the next section.

The DC side of the inverter is connected to a capacitor. The DC capacitor provides a constant DC voltage and the real power necessary to cover the losses of the system. In the steady state, the real power supplied by the source should be equal to the real power demand of the load plus a small power to compensate the losses in the active filter. Thus, the DC capacitor voltage can be maintained at a reference value. However, when the load condition changes the real power balance between the mains and the load will be disturbed. The real power difference is to be compensated by the DC capacitor. This changes the DC capacitor voltage away from the reference voltage. A fuzzy logic controller is applied to maintain the constant voltage across the capacitor by minimizing the error between the capacitor voltage and the reference voltage.

\section{REVIEW OF FUZZY LOGIC CONTROL}

Fuzzy logic uses fuzzy set theory, in which a variable is a member of one or more sets, with a specified degree of membership. Fuzzy logic allow us to emulate the human reasoning process in computers, quantify imprecise information, make decision based on vague and in complete data, yet by applying a "defuzzification" process, arrive at definite conclusions. The block diagram representation of a fuzzy logic controller (FLC) is shown in Fig.3.

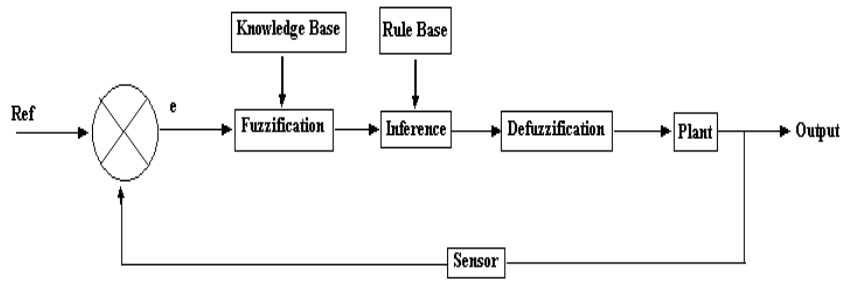

Fig.3.Block diagram of FLC

The FLC mainly consists of three blocks

- Fuzzification

- Inference

- Defuzzification

The details of the above processes are given below.

\section{A. Fuzzification}

The fuzzy logic controller requires that each input/output variable which define the control surface be expressed in fuzzy set notations using linguistic levels. The linguistic values of each input and output variables divide its universe of discourse into adjacent intervals to form the membership functions. The member value denotes the extent to which a variable belong to a particular level. The process of converting input/output variable to linguistic levels is termed as fuzzification.

\section{B. Inference}

The behavior of the control surface which relates the input and output variables of the system is governed by a set of rules. A typical rule would be

\section{If $x$ is $A$ Then $y$ is $B$}

When a set of input variables are read each of the rule that has any degree of truth in its premise is fired and contributes to the forming of the control surface by approximately modifying it. When all the rules are fired, the resulting control surface is expressed as a fuzzy set to represent the constraints output. This process is termed as inference.

\section{Defuzzification}

Defuzzification is the process of conversion of fuzzy quantity into crisp quantity. There are several methods available for defuzzification. The most prevalent one is centroid method, which utilizes the following formula:

$$
\frac{\int(\mu(x) x) d x}{\int \mu(x) d x}
$$

where $\mu$ is the membership degree of output $\mathrm{x}$.

\section{DESIGN OF FUZZY LOGIC CONTROLlER}

\section{A. Fuzzy Logic-based DC Voltage Control}

To design the FLC, variables which can represent the dynamic performance of the plant to be controlled should be chosen as the inputs to the controller. It is common to use the output error (e) and the rate of error (e') as controller inputs. In the case of the fuzzy logic based DC voltage control, the capacitor voltage deviation and its derivative are considered as the inputs of the FLC and the real power (Preg) requirement for voltage regulation is taken as the output of the FLC. The input and output variables are converted into linguistic variables. In this case, seven fuzzy subsets , NL(Negative Large), NM (Negative Medium), NS ( Negative Small), ZE (Zero), PS (Positive Small), PM (Positive Medium) and PL ( Positive large) have been chosen. Membership functions used for the input and output variables used here are shown in Fig.4. As both inputs have seven subsets, a fuzzy rule base formulated for the present application is given in table I.

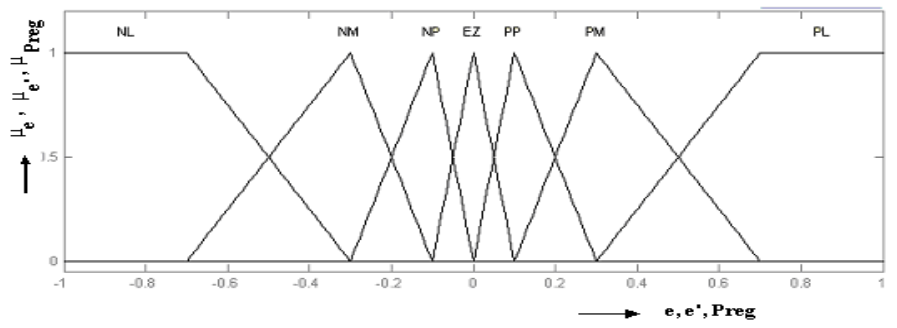

Fig.4. Membership function for the input and output variable 
(b)

\begin{tabular}{|c|c|c|c|c|c|c|c|}
\hline de & NL & NM & NS & $\mathbf{Z E}$ & PS & $\mathbf{P M}$ & PL \\
\hline NL & NL & $\mathrm{NL}$ & NL & NL & NM & NS & ZE \\
\hline NM & NL & $\mathrm{NL}$ & NL & $\mathrm{NM}$ & NS & $\mathrm{ZE}$ & PS \\
\hline NS & $\mathrm{NL}$ & $\mathrm{NL}$ & $\mathrm{NM}$ & NS & ZE & PS & PM \\
\hline $\mathbf{Z E}$ & NL & NM & NS & $\mathrm{ZE}$ & PS & $\mathrm{PM}$ & PL \\
\hline PS & $\mathrm{NM}$ & NS & ZE & PS & $\mathrm{PM}$ & PL & PL \\
\hline $\mathbf{P M}$ & NS & ZE & PS & $\mathrm{PM}$ & PL & $\mathrm{PL}$ & PL \\
\hline PL & $\mathrm{NL}$ & NM & NS & ZE & PS & $\mathrm{PM}$ & PL \\
\hline
\end{tabular}

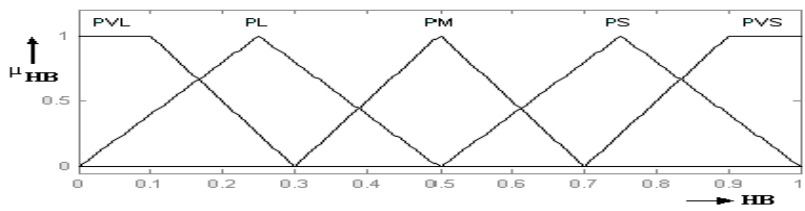

(c)

Fig.5. Membership functions for the input variables (a) $v_{s}(t)$, (b) $\frac{d i_{f a}^{*}}{d t}$ and (c)output variable $\mathrm{HB}$ TABLE II. FUZZY INFERENCE RULE

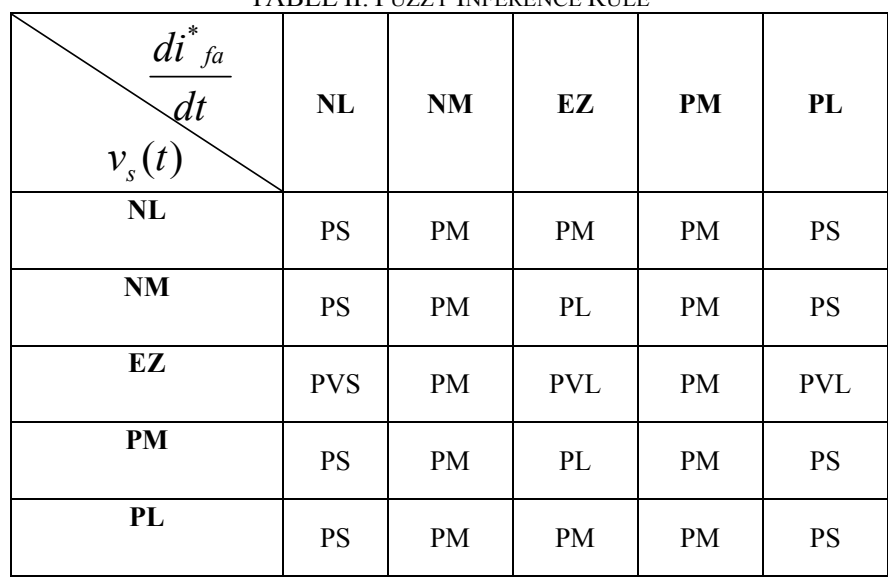

In this method the switching frequency is kept constant and the current error is appreciably reduced ensuring better global stability and insensitivity to parameter variation.

\section{Simulation Results}

This section presents the details of the simulation carried out to demonstrate the effectiveness of the proposed control strategy for the active filter to reduce the harmonics. Fig.6 shows the test system used to carry out the analysis. The test system consists of a three phase voltage source, and an uncontrolled rectifier with RL load. The active filter is connected to the test system through an inductor L. The values of the circuit elements used in the simulation are given in Appendix B. MATLAB/SIMULINK is used to simulate the test system and the proposed shunt active filter.

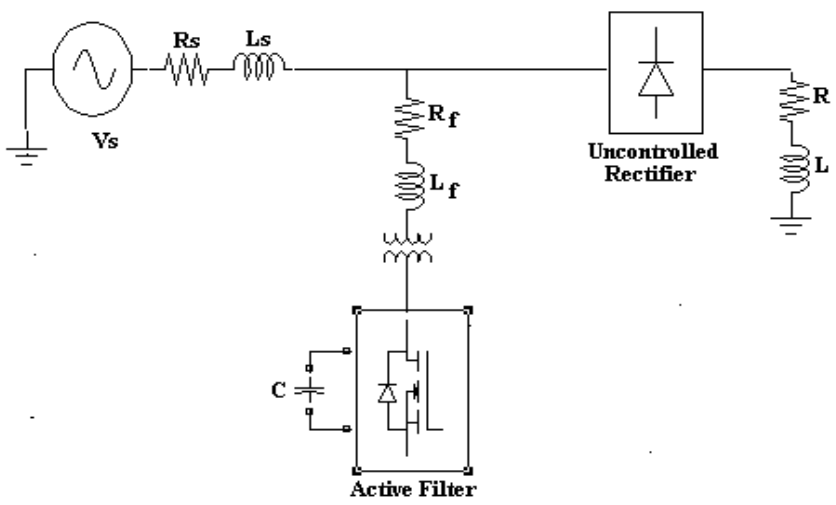

Fig.6. Test system

The three phase load current waveform in the absence of the filter is shown in Fig. 7 (a). Fig 7(b) shows the harmonic 
spectrum of the distorted waveform. The Total harmonic Distortion (THD) of the distorted line current is $26.34 \%$. From the harmonic spectrum, it is evident that, the supply current is distorted due to the dominancy of fifth and seventh harmonic spectral components.

Next, an active filter with fixed hysteresis band current control $(\mathrm{HB}=0.5 \mathrm{~A})$ and PI voltage control is connected in parallel with the load. Figures 8(a) shows the source voltage, source current, and filter current in this case. The THD in this case has decreased from 26.32 to $4.1 \%$.

The performance of the system with fixed hysteresis band control and fuzzy logic-based DC bus voltage control was analyzed and the resultant waveforms are shown in Fig 8 (b). It shows that the source harmonic current has reduced and the THD has decreased from 26.32 to $3.6 \%$. The performance of PI and fuzzy controller in maintaining DC bus voltage is shown in fig.9. It is observed that the DC bus voltage is exactly maintained at the reference value by the fuzzy logic controller, whereas some deviations are present with the PI controller.

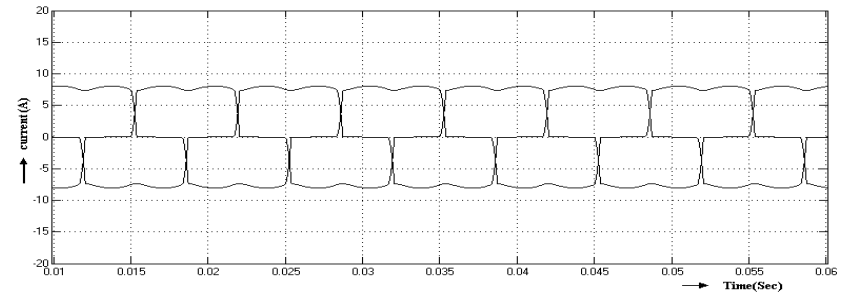

a) Distorted three phase line current

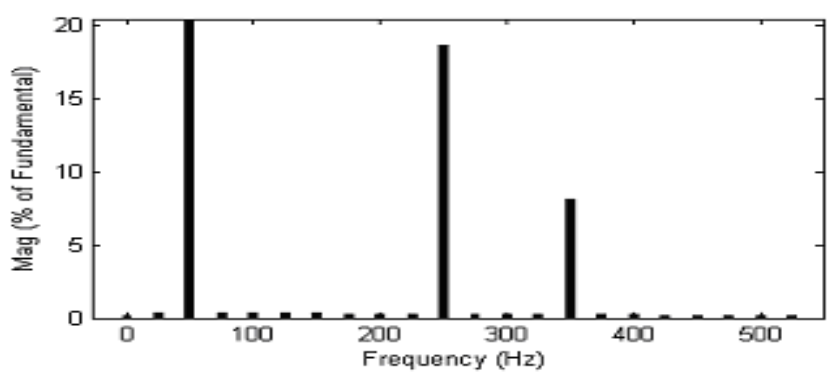

b) Harmonic Spectrum of the line current
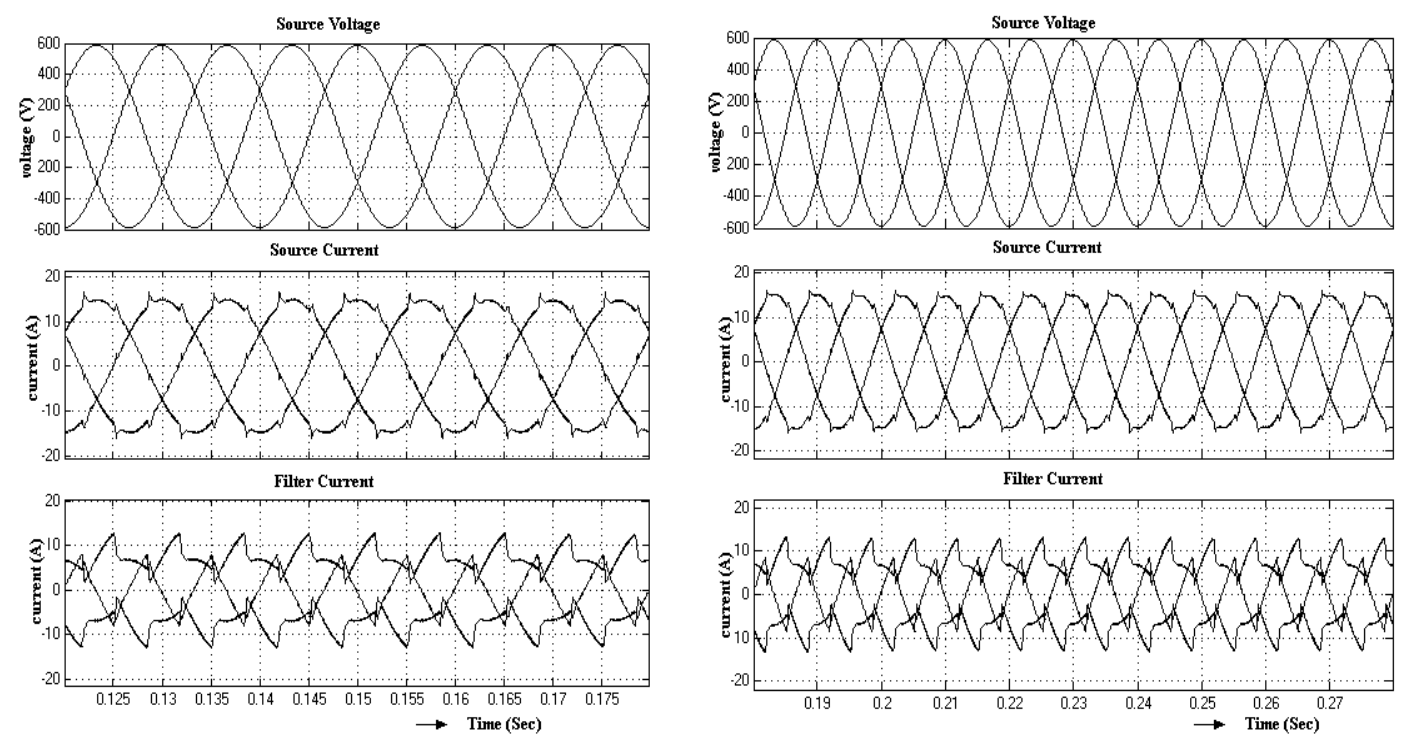

(b)

(a)

Fig. 8. Harmonic Compensation with fixed hysteresis band control with DC bus voltage control using (a) PI control (b) Fuzzy control 


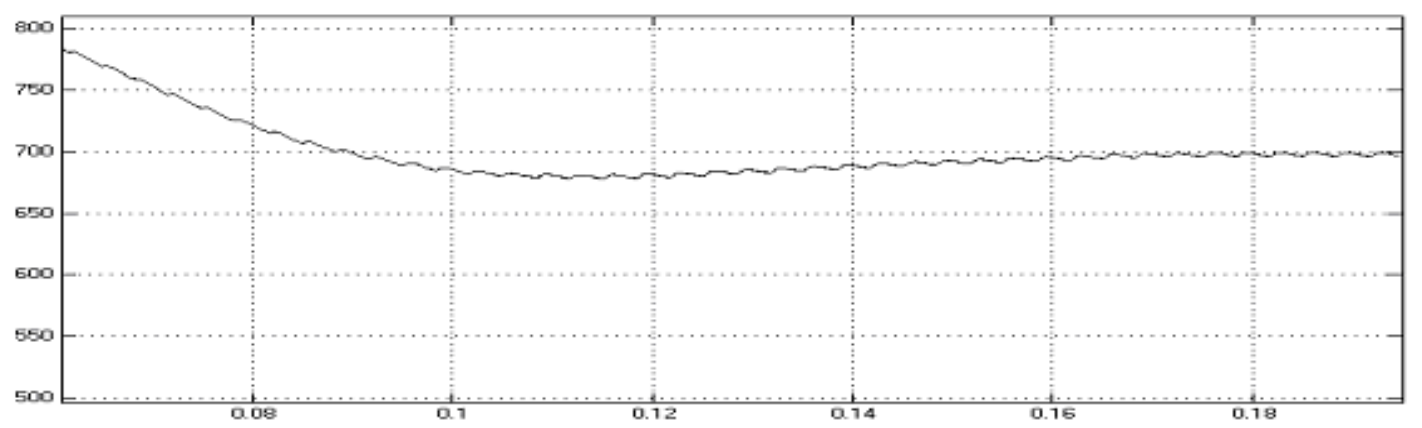

(a) PI Control

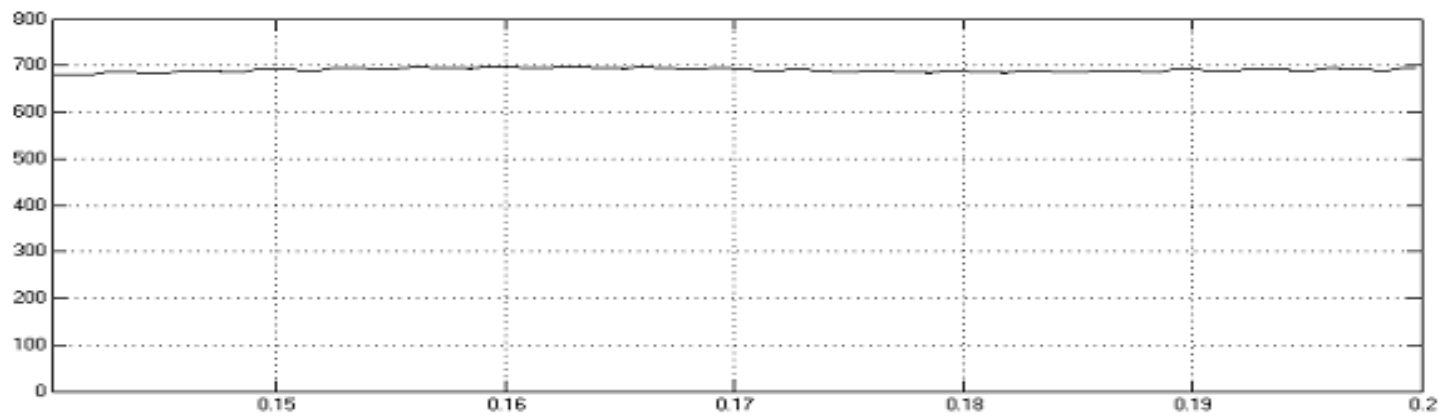

(b) Fuxzy Control

Fig.9. DC bus voltage maintenance-Performance comparison of PI and Fuzzy control
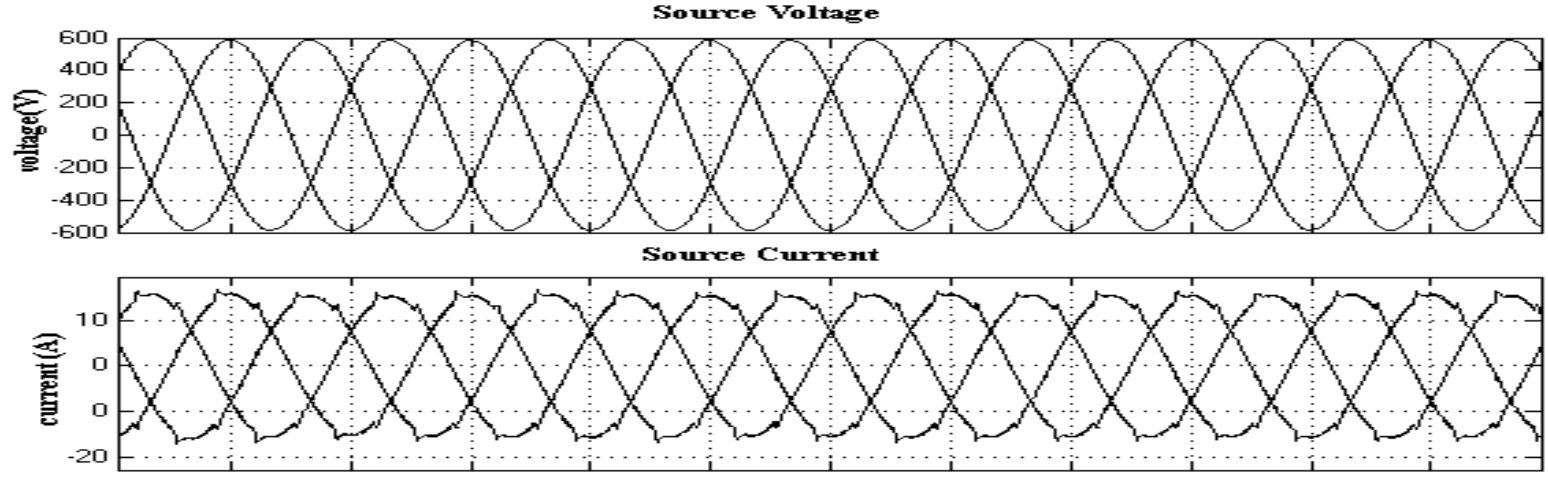

Filter eurrent

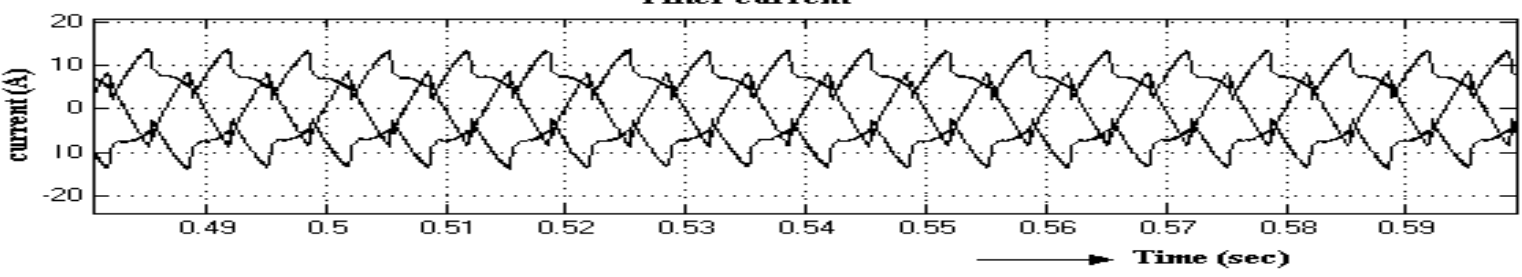

Fig.10.Harmonic compensation with adaptive hysteresis current control 


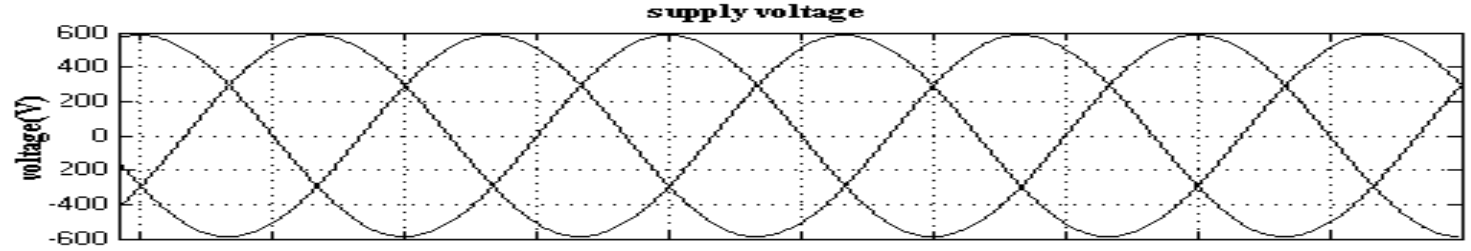

supply current

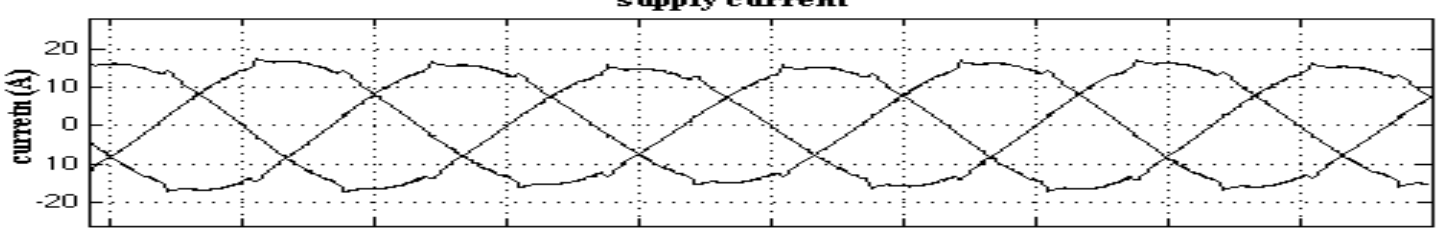

Filter curtent

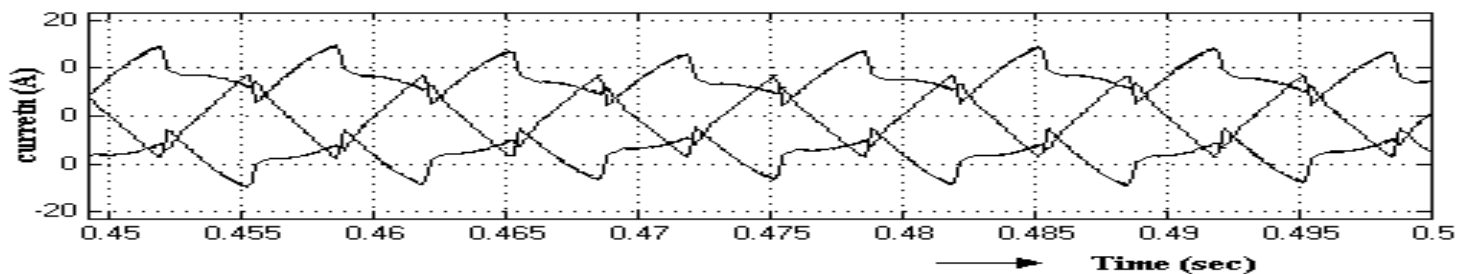

Fig.11.Harmonic compensation with Fuzzy-adaptive hysteresis current control

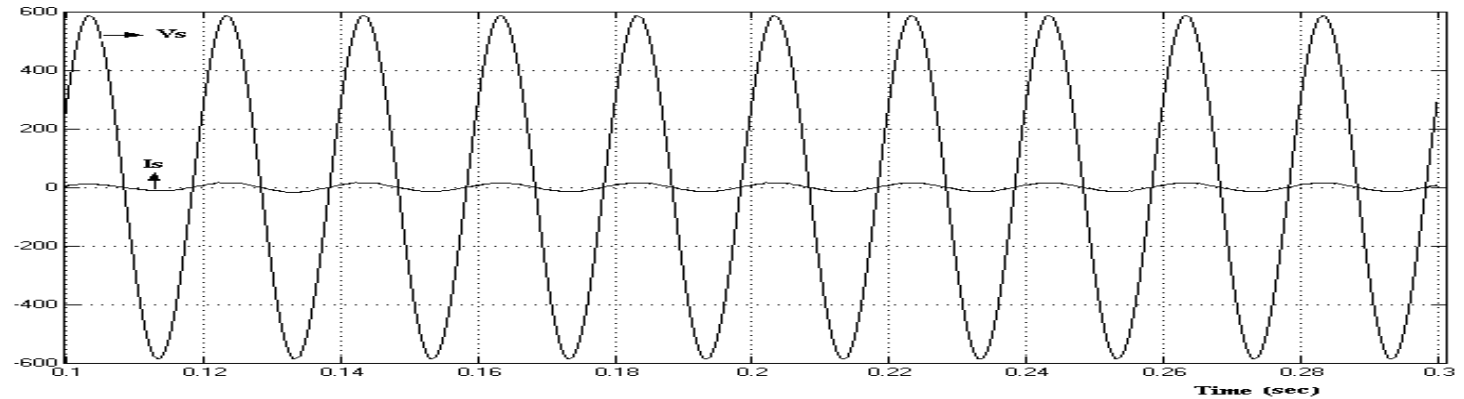

Fig.12.Source voltage and Current

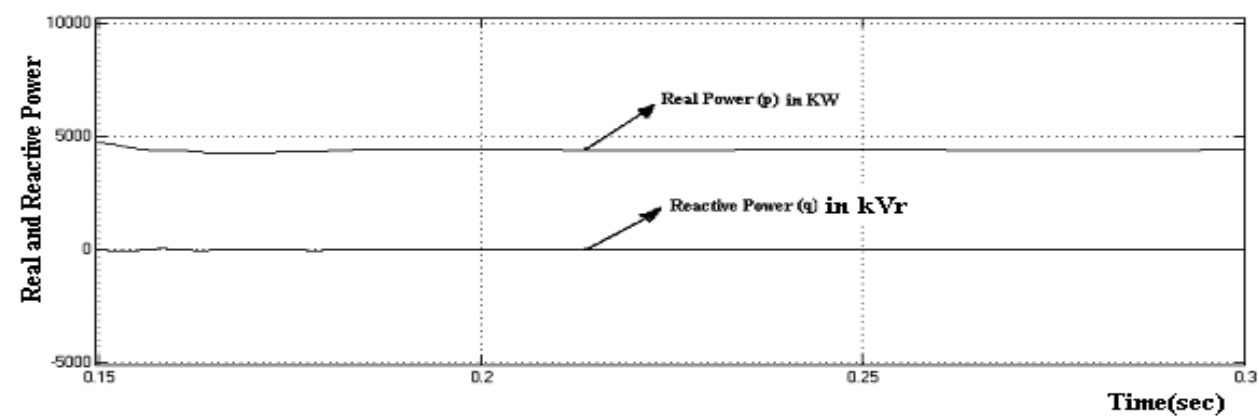

Fig.13. Real and Reactive power supplied by the source to the Load.

TABLE III. HARMONIC CONTENTS OF THE SUPPLY CURRENT

\begin{tabular}{|c|c|c|c|c|c|c|c|c|c|c|c|}
\hline \multirow{2}{*}{$\begin{array}{c}\text { Voltage } \\
\text { Control } \\
\text { Technique }\end{array}$} & \multirow{2}{*}{$\begin{array}{c}\text { Current } \\
\text { Control } \\
\text { Technique }\end{array}$} & \multirow{2}{*}{$\begin{array}{l}\text { THD } \\
\text { (\%) }\end{array}$} & \multicolumn{9}{|c|}{ Individual harmonic Content (\% of Fundamental) } \\
\hline & & & 3 & 5 & 7 & 9 & 11 & 13 & 15 & 17 & 19 \\
\hline \multicolumn{2}{|c|}{ Without Filter } & 26.34 & 0 & 23 & 12 & 0 & 9 & 7 & 0 & 5 & 4 \\
\hline PI & $\begin{array}{c}\text { Fixed } \\
\text { Hysteresis }\end{array}$ & 4.1 & 0.5 & 1.5 & 1.52 & 0.12 & 1.61 & 1.45 & 0.26 & 1.33 & 0.9 \\
\hline Fuzzy & $\begin{array}{c}\text { Fixed } \\
\text { Hysteresis }\end{array}$ & 3.6 & 0.1 & 1.5 & 1.4 & 0.15 & 1.7 & 1.4 & 0.15 & 1.4 & 1 \\
\hline Fuzzy & $\begin{array}{l}\text { Adaptive } \\
\text { Hysteresis }\end{array}$ & 3.2 & 0.09 & 1.2 & 1.3 & 0.04 & 1.4 & 1.3 & 0.008 & 1.2 & 1 \\
\hline Fuzzy & $\begin{array}{c}\text { Fuzzy-adaptive } \\
\text { Hysteresis }\end{array}$ & 2.8 & 0.1 & 1.1 & 1.1 & 0.04 & 1.3 & 1.15 & 0.002 & 1.0 & 0.9 \\
\hline
\end{tabular}


TABLE IV. HARMONIC CONTENTS OF THE SUPPLY VOLTAGE

\begin{tabular}{|c|c|c|c|c|c|c|c|c|c|c|c|}
\hline \multirow{2}{*}{$\begin{array}{c}\text { Voltage } \\
\text { Control } \\
\text { Technique }\end{array}$} & \multirow{2}{*}{$\begin{array}{c}\text { Current } \\
\text { Control } \\
\text { Technique }\end{array}$} & \multirow{2}{*}{$\begin{array}{l}\text { THD } \\
(\%)\end{array}$} & \multicolumn{9}{|c|}{ Individual harmonic Content (\% of Fundamental) } \\
\hline & & & 3 & 5 & 7 & 9 & 11 & 13 & 15 & 17 & 19 \\
\hline PI & $\begin{array}{c}\text { Fixed } \\
\text { Hysteresis }\end{array}$ & 3.4 & 0.0015 & 0.13 & 0.17 & 0.007 & 0.25 & 0.25 & 0.008 & 0.35 & 0.3 \\
\hline Fuzzy & $\begin{array}{c}\text { Fixed } \\
\text { Hysteresis }\end{array}$ & 3.14 & 0.0015 & 0.15 & 0.14 & 0.006 & 0.3 & 0.25 & 0.001 & 0.37 & 0.25 \\
\hline Fuzzy & $\begin{array}{c}\text { Adaptive } \\
\text { Hysteresis }\end{array}$ & 3.0 & 0.006 & 0.12 & 0.15 & 0.018 & 0.26 & 0.25 & 0.024 & 0.35 & 0.28 \\
\hline Fuzzy & $\begin{array}{c}\text { Fuzzy- } \\
\text { adaptive } \\
\text { Hysteresis }\end{array}$ & 2.8 & 0.01 & 0.1 & 0.13 & 0.02 & 0.31 & 0.23 & 0.02 & 0.3 & 0.31 \\
\hline
\end{tabular}

TABLE V. HARMONIC CONTENTS OF THE FILTER CURRENT

\begin{tabular}{|c|c|c|c|}
\hline $\begin{array}{c}\text { Voltage } \\
\text { Control } \\
\text { Technique }\end{array}$ & $\begin{array}{c}\text { Current Control } \\
\text { Technique }\end{array}$ & $\begin{array}{c}\text { Filter } \\
\text { Current THD } \\
\mathbf{( \% )}\end{array}$ & $\begin{array}{c}\text { Average } \\
\text { Switching } \\
\text { Frequency } \\
\text { (KHz) }\end{array}$ \\
\hline PI & Fixed Hysteresis & 31.47 & 16.4 \\
\hline Fuzzy & Fixed Hysteresis & 27.77 & 12 \\
\hline Fuzzy & Adaptive Hysteresis & 25 & 11 \\
\hline Fuzzy & Fuzzy-adaptive & 23 & 10 \\
\hline
\end{tabular}

Table.V shows the percentage of filter switching noise and the average switching frequency

\section{CONCLUSION}

This paper has presented a fuzzy- adaptive hysteresis based current control technique for active filter. The active filter was simulated using MATLAB/Simulink and the performance was analyzed in a sample power system with a source and a non-linear load. The fuzzy-adaptive hysteresis control has quick response time and it keeps the switching frequency nearly constant with good quality of filtering. The simulation results show the efficiency of the fuzzy logic controller in maintaining the DC voltage set point DC.

\section{REFERENCES}

[1] Roger C.Dugan, Mark F. McGranaghan, Surya Santoso and H.Wayne Beaty," Electrical Power System Quality", McGraw -Hill.

[2] J.C.Das,"Power Sytem Analysis-Short Circuit Load Flow and Harmonics", Marcel Dekker Publication.

[3] Bhim Singh, Kamal Al Haddad and Ambrish Chandra," A Review of Active Filters for Power Quality Improvement", IEEE Trans on Industrial Electronics, Vol.46, No.5, October 1999, pp. 960-970.

[4] Zainal Salam, Tan Perng Cheng and Awang Jusoh, " Harmonics Mitigation using Active Power Filter : A Technological Review" Elekrika, Vol.8, No.2, 2006, 17-26.

[5] Lucian Asiminoei, Frede Blaabjerg, Steffan Hansen and Paul Thogersen," Adaptive Compensation of Reactive Power with Shunt Active Power Filters", IEEE Trans on Industry Applications, vol.44, no.3, May/June 2008.

[6] Anushuman Shukla, Arindam Ghosh and Ainash Joshi," Hysteresis current control operation of Flying Capacitor Multilevel Inverter and its Application in Shunt Compensation of Distribution System" IEEE Trans on Power Delivery, Vol 22, No.1, Jan 2007.
[7] M. Kazmierkowsi, L.Malesani," Current Control Techniques for Three Phase Voltage Source PWM converters: A survey", IEEE Trans on Industrial Electronics, vol.45, no.5, pp.691- 703, October 1998.

[8] S. Buso, L. Malesani, P. Mattavelli, " Comparison of current control Techniques for Active power Filter Applications", IEEE Transactions on Industrial Electronics, Vol.45, no.5, pp.722-729, Oct 1998.

[9] E.E.EL-Khoy, A. EL-Sabbe, A.El-Hefnawy, and Hamdy M.Mharous," Three phase active power filter based on current controlled voltage source inverter", Electrical Power and Energy Systems, 28 (2006), 537-547.

[10] Murat kale, Engin Ozdemir,"An Adaptive Hysteresis Band Current Controller for Shunt Active Power Filter", Electrical Power and Energy Systems, 73 (2005), 113-119.

[11] Hirofumi Akagi, Edson H. Watanabe and Mauricio Aredes," The P-Q Theory for Active Fiter Control:Some Problems and Solutions", Revista Controle \& Automacao, Vol.15, No.1, Jan 2004.

[12] S.K.Jain, P.Agrawal and H.O.Gupta,"Fuzzy Logic controlled shunt active power filter for power quality improvement", IEE proceedings in Electrical Power Applications, Vol 149, No.5, September 2002.

[13] Oleg Vodyakho and Chris," Three level Inverter Based Shunt Active Power Filter in Three Phase Three Wire and Four Wire Systems" IEEE Trans on Power Electronics, Vol.24, No.5, May2009.

[14] E.Acha, V.G.Agelidis, O.Anaya-Lara, and T.J.E.Miller,"Power Electronic Control in Electrical Systems", Newnes Power Engineering Series, India, 2006, pp.352-366 chapter 8.

\section{APPENDIX A}

Basically, the three phase instantaneous voltages, $\mathrm{V}_{\mathrm{a}}, \mathrm{V}_{\mathrm{b}}$, $V_{c}$ and currents $I_{a}, I_{b}, I_{c}$ are expressed as instantaneous space vectors on the a-b-c coordinates with each component $2 \pi / 3$ apart from each other. However, the three phase voltages and currents are transformed into orthogonal coordinates, $\alpha$ $\beta$ coordinates. This transformation allows the compliance with the right hand rule for real and reactive power calculation [11]. Fig.1. shows the transformations of the three phase voltages and currents vectors in a-b-c 
coordinates into orthogonal coordinates, $\alpha-\beta$ coordinates.

The instantaneous current and voltage space vector are expressed in terms of instantaneous voltages and currents as,

$$
\begin{aligned}
& \mathrm{V}=\left[\begin{array}{lll}
\mathrm{V}_{\mathrm{a}} & \mathrm{V}_{\mathrm{b}} \mathrm{V}_{\mathrm{c}}
\end{array}\right]^{\mathrm{T}} \\
& \mathrm{I}=\left[\begin{array}{lll}
\mathrm{I}_{\mathrm{a}} & \mathrm{I}_{\mathrm{b}} & \mathrm{I}_{\mathrm{c}}
\end{array}\right]^{\mathrm{T}}
\end{aligned}
$$

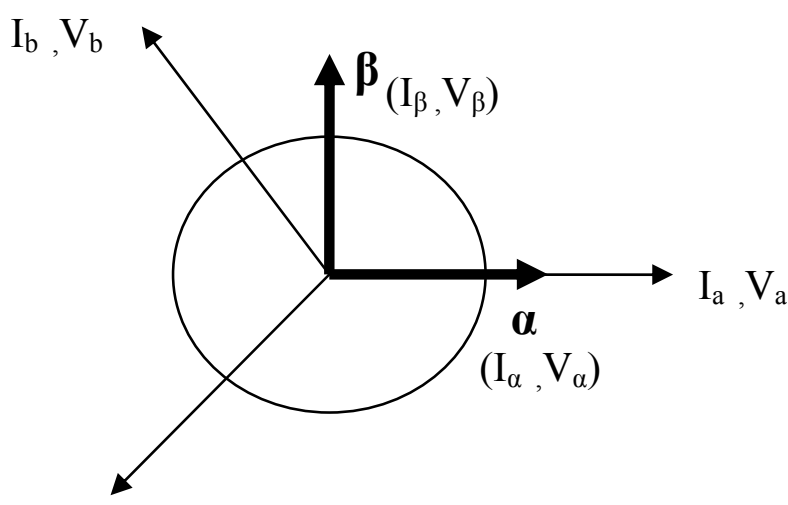

$\mathrm{I}_{\mathrm{c}}, \mathrm{V}_{\mathrm{c}}$

Fig.1. $a-b-c$ to $\alpha-\beta$ Transformation

Instantaneous voltage and currents on the a-b-c coordinates can be transformed into the quadrature $\alpha, \beta$ coordinates by Clarke transformation [14] as follows

$$
\begin{aligned}
& {\left[\begin{array}{l}
V_{\alpha} \\
V_{\beta}
\end{array}\right]=\sqrt{\frac{2}{3}}\left[\begin{array}{cc}
1-\frac{1}{2} & -\frac{1}{2} \\
0 \frac{\sqrt{3}}{2} & \frac{\sqrt{3}}{2}
\end{array}\right]\left[\begin{array}{l}
V_{a} \\
V_{b} \\
V_{c}
\end{array}\right]} \\
& {\left[\begin{array}{c}
I_{\alpha} \\
I_{\beta}
\end{array}\right]=\sqrt{\frac{2}{3}}\left[\begin{array}{cc}
1-\frac{1}{2} & -\frac{1}{2} \\
0 \frac{\sqrt{3}}{2} & \frac{\sqrt{3}}{2}
\end{array}\right]\left[\begin{array}{l}
I_{a} \\
I_{b} \\
I_{c}
\end{array}\right]}
\end{aligned}
$$

Since in a balanced three-phase three wire system neutral current is zero, the zero sequence current does not exist. The power components $\mathrm{p}$ and $\mathrm{q}$ are related to the same $\alpha-\beta$ voltages and currents, and can be written together as given below,

$$
\left[\begin{array}{l}
p \\
q
\end{array}\right]=\left[\begin{array}{cc}
V_{\alpha} & V_{\beta} \\
-V_{\beta} & V_{\alpha}
\end{array}\right]\left[\begin{array}{c}
I_{\alpha} \\
I_{\beta}
\end{array}\right]
$$

where $\mathrm{p}$ is the instantaneous real power and $\mathrm{q}$ is the instantaneous imaginary power. The alternated value of instantaneous real power is calculated back to a-b-c frame which represent the harmonic distortion, given as reference for the current controller. The mean value of the instantaneous real power is usually the only desirable power component. The other quantities can be compensated using a shunt active filter.

To calculate the reference compensation currents in the $\alpha-\beta$ coordinates, the expression (5) is inverted as below:

$$
\left[\begin{array}{l}
i_{c \alpha}{ }^{*} \\
i_{c \beta}{ }^{*}
\end{array}\right]=\left[\begin{array}{cc}
V_{\alpha} & -V_{\beta} \\
V_{\beta} & V_{\beta}
\end{array}\right]\left[\begin{array}{l}
\sim \\
p \\
q
\end{array}\right]
$$

where $\tilde{p}$ is the alternated value of the instantaneous real power. It is the energy per time unity that is exchanged between the power supply and the load, through a-b-c coordinates. $q$ is the instantaneous imaginary power corresponds to the power that is exchanged between the phases of the load but is responsible for the existence of undesirable currents, which circulate between the system phases.

In order to obtain the reference compensation currents in the a-b-c coordinates the inverse of the transformation given in expression (7) is applied.

$$
\left[\begin{array}{l}
i_{c a}^{*} \\
i_{c b}^{*} \\
i_{c c}^{*}
\end{array}\right]=\left[\begin{array}{cc}
1 & 0 \\
-\frac{1}{\sqrt{2}} & -\frac{\sqrt{3}}{2} \\
-\frac{1}{2} & -\frac{\sqrt{3}}{2}
\end{array}\right]\left[\begin{array}{l}
i_{c \alpha}^{*} \\
i_{c \beta}^{*}
\end{array}\right]
$$

\section{APPENDIX B}

System Parameters

\begin{tabular}{|c|c|}
\hline $\begin{array}{c}\text { Supply phase to phase voltage, } \\
\text { frequency }\end{array}$ & $415 \mathrm{~V}(\mathrm{rms}), 50 \mathrm{~Hz}$ \\
\hline Supply line Parameters & $\Omega, \mathrm{Rs}=3 \mathrm{mH}$ \\
\hline Load Resistance & $70 \Omega$ \\
\hline Load Inductance & $37 \mathrm{mH}$ \\
\hline Filter coupling Inductance & $\mathrm{L}_{\mathrm{f}=3 \mathrm{mH}, \mathrm{R}_{\mathrm{f}}=0.5 \Omega}$ \\
\hline Inverter DC bus capacitor & $1 \mathrm{mF}$ \\
\hline DC Voltage Control: & $700 \mathrm{~V}$ \\
Reference Voltage & 0.05 \\
Proportional gain & 0.4 \\
\hline Integral gain & $0.5 \mathrm{~A}$ \\
\hline Hysteresis Band Limit & $2 \mathrm{e}^{-6} \mathrm{sec}$ \\
\hline Sampling Time & \\
\hline
\end{tabular}

